\title{
The CAPS Prediction System and Stock Market Returns
}

\section{Citation}

Avery, Christopher, and Richard Zeckhauser. 2009. The "CAPS" prediction system and stock market returns. HKS Faculty Research Working Papers Series RWP09-011, John F. Kennedy School of Government, Harvard University.

\section{Published Version}

http://web.hks.harvard.edu/publications/workingpapers/citation.aspx?Publd=6577

\section{Permanent link}

http://nrs.harvard.edu/urn-3:HUL.InstRepos:4415901

\section{Terms of Use}

This article was downloaded from Harvard University's DASH repository, and is made available under the terms and conditions applicable to Other Posted Material, as set forth at http:// nrs.harvard.edu/urn-3:HUL.InstRepos:dash.current.terms-of-use\#LAA

\section{Share Your Story}

The Harvard community has made this article openly available.

Please share how this access benefits you. Submit a story.

Accessibility 


\title{
MARVARD Kennedy School JOHN F. KENNEDY SCHOOL OF GOVERNMENT
}

\author{
Faculty Research Working Papers Series
}

\section{The "CAPS" Prediction System and Stock Market Returns}

\author{
Christopher Avery \\ John F. Kennedy School of Government - Harvard University \\ Judith Chevalier \\ School of Management - Yale University \\ Richard Zeckhauser \\ John F. Kennedy School of Government - Harvard University
}

April 2009

RWP09-011

The views expressed in the HKS Faculty Research Working Paper Series are those of the author(s) and do not necessarily reflect those of the John F. Kennedy School of Government or of Harvard University. Faculty Research Working Papers have not undergone formal review and approval. Such papers are included in this series to elicit feedback and to encourage debate on important public policy challenges. Copyright belongs to the author(s). Papers may be downloaded for personal use only. 
The “CAPS” Prediction System and Stock Market Returns

\author{
Christopher Avery \\ Judith Chevalier
}

Richard Zeckhauser

April 2009 


\section{Introduction}

We analyze the informational content of predictions by individual investors about future price movements of individual stocks. Our data consists of more than 1.2 million stock picks provided by more than 60,000 individuals from November 1, 2006 to October 31, 2007. These individuals made predictions through the CAPS open access website created and operated by the Motley Fool company (www.caps.fool.com). We seek to assess the predictive power of CAPS predictions from the perspective of the efficient market hypothesis. That hypothesis suggests that individuals whether amateurs or professionals -- cannot predict future stock market returns, since any publicly available information is instantaneously incorporated into the stock price. The contrary hypothesis emerges from the theory of collaborative filtering, which posits that many individuals - each with limited information - can provide very accurate assessments if their information is elicited in an appropriate fashion. Popular illustrations of the success of collaborative filtering include the eBay rating system, where sellers are rated on their reliability, with a variety of more general examples described in the book The Wisdom of Crowds. However, collaborative filtering has not been demonstrated to be of value in the challenging context of financial markets.

This paper builds on several separate strains of academic literature within finance. First, a vast set of studies assess the ability of institutional investors to surpass market profits without taking on excessive risk. Studies of investment professionals, such as mutual fund managers (Chevalier and Ellison, 1999), newsletter publishers (Metrick, 1999) and analysts (Mikhail, Walther, Willis, 2003) generally conclude that a small percentage of people consistently "beat the market". However, the 
results of these papers suggest that there are relatively few people who possess either the information or ability to successfully pick individual stocks.

A second set of studies supports the conventional wisdom that individual investors perform poorly as stock market investors. Odean and coauthors, in a series of papers, exploit a large dataset of individual customer accounts at a major discount brokerage firm to analyze the results for individuals as traders. Odean (1999) finds that individual investors' purchases tend to underperform their sales by a significant margin. Barber and Odean (2000) show that, on average, the stock choices of individual investors underperform market indices, and that this underperformance is particularly acute for active traders. Barber and Odean (2001a) find that men are more likely to be active traders than women, and that this trading hurts their portfolio returns. They link this evidence to survey results showing that men are more confident in their investing abilities, and conclude that overconfidence in stock-picking ability leads to underperformance. Finally, Barber, Odean, and Zhu (2006) show that stocks purchased heavily by individual investors in a given week tend to outperform other stocks for the next two weeks, but then underperform the market in the subsequent months.

Despite these findings, there is growing evidence that some individual investors have superior information about some assets. For example, Coval, Hirshleifer, and Shumway (2005) demonstrate that individual investors' trades show strong persistence in performance. This suggests that some individuals may be able to earn abnormal profits. Furthermore, a number of papers suggest that the excess performance may result because those individuals concentrate their portfolios in stocks for which they have an informational advantage. For example, Ivkovic and Weisbenner (2005) and 
Massa and Simonov (2006) using U.S. and Swedish data, respectively, find that investments in local stocks outperform non-local investments and in the Swedish case, outperform market benchmarks. Similarly, Ivkovic, Sialm, and Weisbenner (2008), using data on the investments of a large number of individual investors made through a discount broker from 1991 to 1996, find that among households with account balances greater than $\$ 100,000$, those that hold only 1 or 2 stocks outperform those that hold 3 or more stocks by 41 basis points per month. They also show that the excess performance is concentrated in non-S\&P500 stocks that receive little analyst coverage. The authors suggest that these findings are consistent with some investors concentrating their holdings in securities for which they have a true informational advantage. Such an informational advantage would be harder to achieve for stocks that are widely followed.

A final set of related studies considers the effect of the internet on stock market trading and prices. The internet has lowered the cost of stock trading but has also made it possible for individuals to participate in the stock market as commentators on message boards. One common theme of prior research is that the internet may exacerbate behavioral biases that lead to suboptimal investments (Barber and Odean, 2001b), and possibly even create new methods for stock manipulation (Frieder and Zittrain, 2007). A series of recent papers assesses the informational content of postings on message boards such as Yahoo! and Raging Bull as well as the effect of these messages on stock trading and prices. The most robust finding from this literature is that there is a connection between the volume of messages about a stock and future trading of that stock - a high volume of messages tends to predict higher future trading volumes and pricing volatility (Antweiler and Frank, 2004a). In terms of information, message board postings overlap in content with forthcoming news stories (Antweiler and Frank, 2004a), and earnings announcements (Bagnoli, Daniel and Watts, 1999), but message boards promulgate the sooner than traditional media sources. 
Yet there is at best limited evidence that the informational content of message board postings predicts future price movements for individual stocks. Even though message board postings may predict future news articles, the news articles themselves have limited and short-lived predictive power on future stock prices (Tetlock, 2007). Similarly, the assessed correlation between message board content and stock price movements is generally small and short-lived (Das and Chen, 2007, Whitelaw and Tumarkin, 2001, Antweiler and Frank, 2004a), though very unusual volumes of message board activity correlate with substantial next-day price movements for thinly traded microcap stocks (Sabherwal, Sarkar, and Zhang, 2008) and negative future returns for a broader set of stocks (Antweiler and Frank, 2004b).

This paper departs substantially from the previous literature on message board content because of the nature of the data compiled by the Motley Fool CAPS website. CAPS differs from stock message boards in three important ways that facilitate our research. First, CAPS users make specific predictions about the future price of a particular stock; by contrast, analysis of message board postings requires a systematic language-extraction algorithm to classify each message imperfectly as (say) "Buy/Sell/Hold". Second, CAPS is designed to promote reputations of its participants. Each player is rated based on the performance of previous picks, and each player's past history of picks and performance can be viewed by others. Third, CAPS synthesizes the history of past picks to produce a rating for each stock (from the worst rating of "One Star" to the best rating of "Five Stars") that provides a single prediction for each stock at each point in time.

It is important to place this paper in the more general literature on collaborative filtering. The critical element of such filtering is that the views of multiple agents are drawn together to form an overall aggregate picture, say of the quality of a restaurant or website. This field can be further 
broken down between prediction markets and reputation systems. Some websites host competitive prediction markets for trade of shares that will pay off if a particular event occurs (e.g., Hillary Clinton is nominated), and their trading markets are analogous to futures markets in the context of finance. ${ }^{1}$ There are also prediction markets, conducted in the spirit of CAPS, where individuals make predictions without having automatic financial stakes in the outcomes. The success of such systems still depends on capturing disparate information from many individuals. The famed and long established Delphi Method brings together a group of experts to aggregate their opinions. Experience suggests that this system is often highly successful in predicting business outcomes. ${ }^{2}$

Reputation systems generally provide no financial rewards for raters, who like the participants in CAPS, provide information on behalf of the community. On eBay, for example, participants rate individual transactions with others as buyers and sellers. The resulting scores for participants (number of rankings and percent positive) have been sufficiently reliable to allow a vast number of individuals to conduct successful exchange transactions on eBay (Resnick and Zeckhauser, 2002). CAPS is a reputation system in the sense that the opinions of individuals are aggregated. It differs from eBay in three important respects. First, the method for aggregation is not public. Second, individuals rank on the basis of their overall judgment of a stock, not their personal experience. Third, unlike eBay, CAPS is designed so that raters improve their own reputation for providing valuable information. Amazon.com is an example of a website where reviewers receive public reputations for the quality of their reviewers. A distinction between Amazon.com and CAPS is that the quality of reviewers on Amazon is assessed by whether users of the site "found this review helpful." In CAPS, a participant's reputation score is a function of the objective performance of the

\footnotetext{
${ }^{1}$ Wolfers and Zitzewitz (2004) provides a helpful review of such mechanisms outside direct financial markets.

${ }^{2}$ See Linstone and Turoff (1975) and Hogarth (1977) for early discussions of the Delphi Method, and Sunstein (2006) for a more general and recent review.
} 
stocks she/he picked. Similar to Amazon.com (but in contrast to eBay), it is not clear what material benefit a participant gains from garnering a positive reputation on CAPS.

The paper proceeds as follows. Section 2 describes the data. We then provide descriptive statistics at the level of individual predictions in Section 3 and at the level of individual stocks in Section 4. We spend some time documenting these descriptive statistics because the results from our sample are quite striking. On average, each "Buy" prediction outperforms each "Sell" prediction by an average of 12.9 percentage points in the next twelve months of trading. Similarly, stocks with the highest CAPS rating of "5 Stars" outperform stocks with the lowest CAPS rating of "1 Star" by an average of 12.4 percentage points in the next six months of trading, corresponding to a difference in annualized returns of approximately 25 percentage points. Section 5 then uses a four-factor model to identify excess returns for portfolios for stocks based on CAPS ratings. Section 6 reports the results of a sensitivity analysis for a set of adjusted portfolios. Section 7 concludes.

\section{Data}

The data for this study was provided by the Motley Fool company under a license agreement with Harvard University. The data contains all stock market picks from the CAPS website from November 1, 2006 through October 31, 2007. The Motley Fool compiles information on each participant's picks, and uses this information to rate both players and stocks. CAPS only allows picks for stocks that have a price of at least $\$ 1.50$ per share and a market cap of at least $\$ 100$ million at any given time.

The CAPS website highlights the fact that it places priority on picks from participants with the highest player ratings. Each participant's player rating is publicly available and represents that 
participant's current percentile ranking (from 0 to 100) based on the market performance of past picks. ${ }^{3}$ Participants with ratings of 80 or above, representing those in the top fifth of player ratings, are labeled as "CAPS All Stars", and their picks are highlighted throughout the website.

As part of the data for the study, Motley Fool also provided the daily rankings of these stocks from "1-Star" (the worst) to "5-Stars" (the best) for this one-year period. The CAPS website states that these ranking are based on a proprietary algorithm that gives extra weight to predictions by highlyrated players and to recent picks. ${ }^{4}$ In general, each star rating corresponds to a quintile of stocks based on an underlying (unreported) CAPS cardinal ratings for those stocks. That is, "1 Star" stocks consist of those stocks at the $20^{\text {th }}$ percentile or below in cardinal ranking, whereas " 5 Star" stocks consist of those stocks at the $80^{\text {th }}$ percentile or above in cardinal ranking based on past CAPS picks. We had no knowledge of the specific details about the proprietary system used to generate these rankings, and made no effort to identify its properties.

The data provided by Motley Fool for the study includes 1,207,598 distinct picks encompassing 6,899 different stocks and 62,408 different usernames. ${ }^{5}$ We exclude 1,245 picks that were generated from the CAPS ratings (these are identified by player names "CAPS5StarIndex", "CAPS1StarIndex" and "CAPS5star1star") and 2,210 picks that had initial dates prior to November 1, 2006 (these picks were "re-started" by participants during the sample period).

\footnotetext{
${ }^{3}$ Participants with fewer than seven CAPS picks are not given player ratings.

${ }^{4}$ See $h$ ttp://caps.fool.com/help.aspx for publicly available information on the CAPS rating algorithm.

${ }^{5}$ An individual person can register more than once on the CAPS website and make picks using multiple "player names". The exact number of distinct participants who have made picks on the CAPS website is unknown.
} 
We compiled stock price data from the Center for Research and Security Prices (CRSP) for the eighteen month period from November 1, 2006 (the official launch date for CAPS) to May 1, 2008 (six months after the end of our sample of CAPS stock picks). Since CRSP and CAPS use different identification numbers for stocks, we matched stocks across the two databases by ticker symbol and by name. We were able to match 6,140 stocks using this system. Yahoo Finance enabled us to add pricing data for 170 additional stocks. ${ }^{6}$ We also downloaded the price history for the S\&P 500 Index from CRSP. Our matched database of stock picks from CAPS and stock prices from CRSP/Yahoo includes 6,310 out of 6,899 stocks in the picks sample. It incorporates 1,193,481 CAPS picks, comprising $98.8 \%$ of the picks in the original data set. The remaining unmatched picks are primarily for small and often de-listed stocks.

For this study, we focus attention on stocks that received at least 20 picks in CAPS during either (1) the six month period from November 1, 2006 to April 30, 2007 or (2) the six month period from May 1, 2007 to October 31, 2007. The vast majority of the picks in the database are for stocks that meet this criterion, including 1,171,428 CAPS picks ( $97.1 \%$ of all picks in the database) and 4,796 stocks.

We classify these stocks for each trading day during the sample period on the basis of both their sizes and returns in the previous year. Specifically, we classify companies with market caps of more than $\$ 5$ Billion as "Large Caps", companies with market caps between $\$ 1$ and $\$ 5$ Billion as

\footnotetext{
${ }^{6}$ These 170 stocks had CAPS ratings on at least one of November 1, 2006, May 1, 2007, or October 31, 2007. One distinction between the CRSP data and the Yahoo Finance data is that stock prices listed in Yahoo Finance have already been adjusted to account for dividends and splits. We used a standard method to adjust the CRSP prices for dividends and splits, essentially assuming that dividend distributions are reinvested in the given stock. We made one adjustment to the Yahoo data, assigning the closing price on a day where a stock was not traded to be the opening price on the next that the stock is traded. By contrast, Yahoo uses a default procedure of listing the closing price to equal the previous day's closing price on a day that a stock is not traded. .
} 
"Medium Caps" and companies with market caps less than \$1 Billion as "Small Caps". ${ }^{7} \mathrm{We}$ classify companies in the top three deciles (top 30\%) for stock market returns over the past trading year as "High Momentum" and companies in the bottom three deciles (bottom 30\%) for stock market returns of the past trading year as "Low Momentum".

The CAPS database provided to us did not include a history of player ratings for participants. Though the CAPS website does not describe the details of its stock rating algorithm, it does provide complete information about its algorithm for rating players, which gives $2 / 3$ weight to "Total Score" and 1/3 weight to "Accuracy" of past picks. To assess the importance of player ratings, we created simulated player ratings based on this algorithm for the course of the sample period on a daily basis. We believe that these simulated ratings reasonably approximate the actual history of player ratings, though we know that they deviate somewhat from actual player ratings. ${ }^{9}$

\section{Preliminary Results: Individual Picks and Stock Performance}

With the benefit of less than one year of hindsight, our eighteen month sample period of stock prices from November 1, 2006 to May 1, 2008 already appears to be anomalous because of the huge decline in stock prices in the last six months of 2008. Table 1 provides descriptive statistics for stock market returns for the three successive six-month periods for these eighteen months. As noted in the first row, stock prices for these companies increased by almost $12 \%$ through May 1 ,

\footnotetext{
${ }^{7}$ CRSP provides the number of shares outstanding for each stock, so we compute the market cap for stocks listed in CRSP for each trading day in the sample by simply multiplying this number of shares by (unadjusted) closing price. We were unable to find similar information in Yahoo Finance for most of the 170 stocks where we used Yahoo to compile historical price information; so we estimated the historical market caps for this subset of stocks based on the current market caps listed for these companies on the CAPS website as of February, 2009.

${ }^{8}$ We compute momentum based on ordinal ranking of one-year returns for all ranked stocks, which does not precisely correspond to the set of stocks used by French and others to compute daily returns on portfolios of high and low momentum stocks.

${ }^{9}$ For example, one distinction between simulated and actual player ratings is that the actual player ratings include information for picks made prior to November 1, 2006.
} 
2007 and continued to rise during the next six months before giving up most of these gains at the end of 2007 and the early part of 2008.

In addition, as shown in the next three rows of Table 1, this was a particularly good period for investments in "Large Caps" relative to others, and a particularly bad period for investments in "Small Caps", whose returns were at least five percentage points less than "Medium Caps" in each of these three six month periods. The sample period was also relatively poor for "Low Momentum" stocks, which underperformed "High" and "Medium Momentum" stocks in each six month subperiod from November 1, 2006 to May 1, 2008.

Table 1: Six Month Returns for Stocks with Different Attributes November 1, 2006 to May 1, 2008

\begin{tabular}{|c|c|c|c|}
\hline & 11/1/06 to $5 / 1 / 07$ & $5 / 1 / 07$ to $10 / 31 / 07$ & $10 / 31 / 07$ to $5 / 1 / 08$ \\
\hline 1. All Stocks & $11.7 \%$ & $4.5 \%$ & $-14.0 \%$ \\
\hline 2. Large Cap & $12.2 \%$ & $8.8 \%$ & $-8.0 \%$ \\
\hline 3. Medium Cap & $14.7 \%$ & $6.6 \%$ & $-9.8 \%$ \\
\hline 4. Small Cap & $8.9 \%$ & $1.4 \%$ & $-19.3 \%$ \\
\hline 5. High Momentum & $12.2 \%$ & $8.8 \%$ & $-10.3 \%$ \\
\hline 6. Medium Momentum & $12.7 \%$ & $7.6 \%$ & $-9.2 \%$ \\
\hline 7. Low Momentum & $9.8 \%$ & $-4.3 \%$ & $-17.4 \%$ \\
\hline
\end{tabular}

* These tabulations are based on the attributes of stocks at the beginning of each six month period. The results are simple averages, and are not annualized.

Table 2 provides descriptive statistics for the sample of CAPS stock picks On average, CAPS participants, like most stock market analysts, were relatively bullish, producing a ratio of about five positive picks per negative pick. Further CAPS participants were relatively pessimistic about both Small Caps and Low Momentum stocks (Rows 4 and 9 of Table 2), and as noted in Table 1, this pessimism was borne out in conspicuous fashion during the six months of stock trading subsequent to our sample period of picks. Given the short sample period, we cannot distinguish between two 
possible explanations for these trends in picks: (1) CAPS participants were prescient in anticipating that Small Caps and Low Momentum stocks were poor choices for this specific time period; (2) CAPS participants are generally inclined against these two groups of stocks and their predilections coincidentally matched the short-term trends in future stock prices during and subsequent to the sample period. Our formal analysis of the information contained in CAPS picks corrects for both of these market trends.

Table 2: Descriptive Statistics for Picks

\begin{tabular}{|c|c|c|c|}
\hline & Number of Picks & $\begin{array}{c}\text { Percentage of } \\
\text { Picks }\end{array}$ & $\begin{array}{c}\text { Percent Positive } \\
\text { Picks }\end{array}$ \\
\hline 1. Whole Sample & $1,171,428$ & $100 \%$ & $83.4 \%$ \\
\hline 2. Large Cap (> \$5 B) & 421,560 & $36.0 \%$ & $87.2 \%$ \\
\hline 3. Medium Cap (\$1B - \$5B) & 311,647 & $26.6 \%$ & $85.5 \%$ \\
\hline 4. Small Cap ( < \$1 B) & 433,654 & $37.0 \%$ & $78.4 \%$ \\
\hline 5. S\&P 500 Company & 308,130 & $26.3 \%$ & $84.4 \%$ \\
\hline 6. Not S\&P 500 Company & 863,298 & $73.7 \%$ & $83.0 \%$ \\
\hline 7. High Momentum & 407,373 & $34.8 \%$ & $88.6 \%$ \\
\hline 8. Medium Momentum & 366,619 & $31.3 \%$ & $86.8 \%$ \\
\hline 9. Low Momentum & 312,464 & $26.7 \%$ & $74.4 \%$ \\
\hline $\begin{array}{l}\text { 10. First Six Months } \\
\text { (11/1/2006 to 4/30/2007) }\end{array}$ & 531,084 & $45.3 \%$ & $84.2 \%$ \\
\hline $\begin{array}{l}\text { 11. Second Six Months } \\
\text { (5/1/2007 to 10/31/2007) }\end{array}$ & 640,344 & $54.7 \%$ & $82.6 \%$ \\
\hline 12. Player Rating >= 80 & 279,267 & $23.8 \%$ & $76.2 \%$ \\
\hline $\begin{array}{l}\text { 13. Player Rating between } \\
50 \text { and } 80\end{array}$ & 225,585 & $19.3 \%$ & $83.2 \%$ \\
\hline 14. Player Rating $<50$ & 260,330 & $22.2 \%$ & $82.0 \%$ \\
\hline 15. No Player Rating & 406,246 & $34.7 \%$ & $89.2 \%$ \\
\hline
\end{tabular}

* The percentages for picks by market cap and by momentum do not add to $100 \%$ because market cap information was not available for 4,567 picks ( $0.4 \%$ of the sample) and because returns for the previous year, necessary for computation of momentum, were not available for 84,972 picks ( $7.3 \%$ of the sample). 
Rows 10 and 11 of Table 2 compare picks in the first half of the sample to picks in the second half of the sample. The substantial increase in picks in the second half of the sample suggests that CAPS became more popular in the first months after its launch. In addition, CAPS participants were slightly more pessimistic in their picks during the second six months of the sample period. However, the difference in the percentages of positive picks is small and does not suggest that the participants anticipated the dramatic decline in the stock market that began in late spring 2008.

Rows 12 through 15 of Table 2 provide descriptive statistics based on our simulated ratings for the participants at the time of each pick. We only compute estimated ratings for players with at least seven prior picks during the sample period, and as a result, a bit more than one-third of picks were made by a player we classify as unrated. A disproportionate number of picks were made by players with simulated ratings of 80 or above. The rating procedure guarantees that $20 \%$ of rated players have ratings in this range, and yet they produce nearly $40 \%$ of the picks from ranked players during the sample period. ${ }^{10}$ High-ranked players were more pessimistic in their picks than other participants; unrated players were more optimistic.

Table 3a provides descriptive statistics for future stock market returns subsequent to positive and negative picks. Due to the general decline in market prices during the first half of 2008, the average 12-month return for both positive and negative picks is negative. However, positive picks significantly outperformed negative picks, with the difference in performance growing steadily over a twelve month period subsequent to the date that picks were made.

\footnotetext{
${ }^{10}$ There are two likely explanations for this phenomenon. First, since the rankings are based, in part, on total score, a player with a positive average score per pick will gain a higher ranking than another player with the same score per pick and fewer picks. Thus, the ranking system provides an incentive to make large numbers of picks, and may thereby induce high-ranking players to submit unusually large numbers of picks in order to maintain and increase their ratings. Second, low-ranked players may become discouraged and could even decide to abandon a current player name and begin again with a new player name.
} 
Columns 4 and 5 of Table 3 a compare the returns on the S\&P 500 Index for positive and negative picks. They allow for the possibility that the difference in stock returns between the two may reflect differences in the timing of picks rather than specific information about the likely future performance of individual stocks. In fact, there is little difference between the change in the S\&P index after positive and negative picks. Thus, CAPS data provides no evidence that stock pickers can either time the market or determine overall market direction.

Table 3a: Summary Statistics for Stock Performance All Picks, November 1, 2006 to October 31, 2007

\begin{tabular}{|c|c|c|c|c|}
\hline & Positive Picks & Negative Picks & $\begin{array}{c}\text { SP500 Return } \\
\text { after Pos Picks }\end{array}$ & $\begin{array}{c}\text { SP500 Return } \\
\text { after Neg Picks }\end{array}$ \\
\hline 3 months & $1.6 \%$ & $-4.7 \%$ & $0.3 \%$ & $0.4 \%$ \\
\hline 6 months & $-0.1 \%$ & $-9.7 \%$ & $-1.7 \%$ & $-2.0 \%$ \\
\hline 9 months & $-1.7 \%$ & $-14.3 \%$ & $-4.7 \%$ & $-4.5 \%$ \\
\hline 12 months & $-8.9 \%$ & $-21.8 \%$ & $-11.2 \%$ & $-11.1 \%$ \\
\hline Number of Picks & 976,468 & 194,960 & 976,468 & 194,960 \\
\hline
\end{tabular}

As discussed above, the previous literature indicates that some individual investors may have informational advantages in analyzing some stocks. Ivcovich, Sialm, and Weisbenner (2008) finds superior performance is found more frequently amongst stocks that are not in the S\&P500, suggesting that informational advantages are more difficult to achieve for more well-analyzed stocks. Table $3 \mathrm{~b}$ repeats the analysis of Table $3 \mathrm{a}$ for S\&P 500 stocks, which represent about $26 \%$ of CAPS picks. Once again, average future returns for positive picks are dramatically and significantly higher than average future returns for negative picks, with similar patterns for the change in the difference in returns for each time period after a pick was made. This suggests that individual CAPS picks are about equally informative for both S\&P 500 stocks and for lesser-known stocks. 
Table 3b: Summary Statistics for Stock Performance SP500 Picks, November 1, 2006 to October 31, 2007

\begin{tabular}{|c|c|c|c|c|}
\hline & Positive Picks & Negative Picks & $\begin{array}{c}\text { SP500 Return } \\
\text { after Pos Picks }\end{array}$ & $\begin{array}{c}\text { SP500 Return } \\
\text { after Neg Picks }\end{array}$ \\
\hline 3 months & $1.2 \%$ & $-3.4 \%$ & $0.5 \%$ & $0.5 \%$ \\
\hline 6 months & $0.6 \%$ & $-6.3 \%$ & $-1.3 \%$ & $-1.5 \%$ \\
\hline 9 months & $-0.6 \%$ & $-11.6 \%$ & $-4.2 \%$ & $-4.0 \%$ \\
\hline 12 months & $-6.7 \%$ & $-18.7 \%$ & $-10.5 \%$ & $-10.6 \%$ \\
\hline Number of Picks & 260,200 & 47,930 & 260,200 & 47,930 \\
\hline
\end{tabular}

Tables $4 \mathrm{a}$ and $4 \mathrm{~b}$ combine the results for positive and negative picks using average pick score, as defined by CAPS as a measure of the performance for each pick. Formally, SCORE is defined as

SCORE $=$ Market Return - Index Return $\quad$ for positive picks;

SCORE $=$ Index Return - Market Return for negative picks.

That is, the "Score" simply measures the excess return in percentage points for each pick relative to the S\&P 500 index.

Table 4a: Pick Scores for Future Returns

All Picks, November 1, 2006 to October 31, 2007

\begin{tabular}{|c|c|c|c|c|c|c|c|}
\hline & All Picks & $\begin{array}{l}\text { First Six } \\
\text { Months }\end{array}$ & $\begin{array}{l}\text { Last Six } \\
\text { Months }\end{array}$ & $\begin{array}{l}\text { Player } \\
\text { Rating } \\
\text { > 80 }\end{array}$ & $\begin{array}{l}\text { Rating } \\
\text { Between } \\
\mathbf{5 0} \text { and 80 }\end{array}$ & $\begin{array}{l}\text { Player } \\
\text { Rating }< \\
\mathbf{5 0}\end{array}$ & $\begin{array}{l}\text { No Player } \\
\text { Rating }\end{array}$ \\
\hline 3 months & $2.0 \%$ & $1.5 \%$ & $2.4 \%$ & $3.0 \%$ & $2.1 \%$ & $1.5 \%$ & $1.5 \%$ \\
\hline 6 months & $2.6 \%$ & $3.0 \%$ & $2.3 \%$ & $3.9 \%$ & $2.5 \%$ & $2.0 \%$ & $2.2 \%$ \\
\hline 9 months & $4.1 \%$ & $4.3 \%$ & $3.9 \%$ & $5.8 \%$ & $4.0 \%$ & $3.2 \%$ & $3.6 \%$ \\
\hline 12 months & $3.8 \%$ & $4.7 \%$ & $3.0 \%$ & $4.8 \%$ & $3.3 \%$ & $2.9 \%$ & $3.7 \%$ \\
\hline & $1,171,428$ & 531,084 & 640,344 & 279.267 & 504,852 & 260,330 & 406,246 \\
\hline
\end{tabular}

Table 4b: Pick Scores for Future Returns

Picks for SP500 Companies, November 1, 2006 to October 31, 2007

\begin{tabular}{|c|c|c|c|c|c|c|c|}
\hline & All Picks & $\begin{array}{l}\text { First Six } \\
\text { Months }\end{array}$ & $\begin{array}{l}\text { Last Six } \\
\text { Months }\end{array}$ & $\begin{array}{l}\text { ALL } \\
\text { STAR }\end{array}$ & $\begin{array}{l}\text { Player } \\
\text { Rating }> \\
\mathbf{5 0}\end{array}$ & $\begin{array}{l}\text { Player } \\
\text { Rating }< \\
\mathbf{5 0}\end{array}$ & $\begin{array}{l}\text { No Player } \\
\text { Rating }\end{array}$ \\
\hline 3 months & $1.3 \%$ & $0.5 \%$ & $2.0 \%$ & $2.4 \%$ & $1.5 \%$ & $1.0 \%$ & $0.9 \%$ \\
\hline 6 months & $2.4 \%$ & $2.0 \%$ & $2.8 \%$ & $3.6 \%$ & $2.6 \%$ & $2.0 \%$ & $2.1 \%$ \\
\hline 9 months & $4.2 \%$ & $3.8 \%$ & $4.5 \%$ & $6.1 \%$ & $4.4 \%$ & $3.3 \%$ & $3.8 \%$ \\
\hline 12 months & $4.5 \%$ & $4.5 \%$ & $4.5 \%$ & $5.7 \%$ & $4.5 \%$ & $3.6 \%$ & $4.5 \%$ \\
\hline & 308,130 & 146,359 & 161.771 & 50,967 & 32,022 & 64,115 & 140,026 \\
\hline
\end{tabular}


The last four columns in Tables $4 \mathrm{a}$ and $4 \mathrm{~b}$ compare the results for picks by players by player rating category. Picks by players with very high ratings produce higher average scores over time, reflecting better stock market performance, than picks by players by very low ratings. However, these differences appear to be relatively small. Further, even picks by players with quite low ratings - presumably the least predictive among all picks in the CAPS system - produce significantly positive scores over time. Indeed, they perform only slightly worse than picks by players who have no track record and are unrated. These results suggest that there are no truly bad raters among CAPS participants.

The results of simple regressions in Table 5 complete our descriptive analysis at the level of individual CAPS picks. In each regression, a stock pick is the unit of analysis, with six-month pick score (six month excess return vs. S\&P 500 index) as the dependent variable. These regressions are designed to present suggestive evidence on the relative importance of the factors identified in Tables 1 through 4 in predicting future stock price returns.

We use dummy variables to characterize three groups of player ratings (Rows 1 through 3 of Table 5), two categories of stocks based on market caps (Rows 4 and 5 of Table 5) and two categories of stocks based on the translation of previous year's returns into a "momentum" category (Rows 6 and 7 of Table 5). The omitted categories for each of these dummy variables are, in turn, "Unrated Player", "Medium Cap Stock", and "Medium Momentum Stock".

Thus, the regression coefficents presented in Table 5 can be interpreted as the change in predicted pick score relative to the omitted category. The constant term in each regression represents the estimated pick score for unranked players for "Medium Cap" and "Medium Momentum" stocks 
(assuming that market cap and momentum rankings are included in the regression specification).

These constant terms are positive and statistically significant in every specification, indicating once again that even unranked players perform significantly better than random in picking stocks.

Table 5: Regression Analysis for Individual Picks

\begin{tabular}{|c|c|c|c|c|c|c|c|}
\hline & (1) & (2) & (3) & (4) & (5) & (6) & (7) \\
\hline \multirow[t]{2}{*}{ All-Star Player } & 0.017 & 0.025 & 0.017 & 0.018 & 0.025 & 0.014 & 0.038 \\
\hline & $(21.54)$ & $(31.01)$ & $(21.19)$ & (22.09) & $(30.90)$ & $(11.27)$ & (34.59) \\
\hline \multirow[t]{2}{*}{ Above Avg Player } & 0.004 & 0.008 & 0.003 & 0.003 & 0.008 & 0.006 & 0.015 \\
\hline & $(4.16)$ & $(9.74)$ & $(4.05)$ & $(3.73)$ & $(8.93)$ & $(4.54)$ & $(12.84)$ \\
\hline \multirow[t]{2}{*}{ Below Avg Player } & -0.002 & -0.003 & -0.002 & & 0.003 & 0.002 & 0.009 \\
\hline & $(2.59)$ & $(2.78)$ & $(2.67)$ & & $(4.01)$ & $(1.36)$ & $(8.35)$ \\
\hline \multirow[t]{2}{*}{ Large Cap } & & 0.006 & & & 0.006 & -0.008 & 0.017 \\
\hline & & $(8.12)$ & & & $(7.36)$ & $(7.45)$ & (16.98) \\
\hline \multirow[t]{2}{*}{ Small Cap } & & -0.045 & & & -0.044 & -0.027 & -0.059 \\
\hline & & (61.07) & & & $(59.53)$ & $(24.29)$ & $(59.19)$ \\
\hline S\&P 500 Comp. & & & $\begin{array}{r}-0.001 \\
(1.06)\end{array}$ & & & & \\
\hline \multirow[t]{2}{*}{ High Momentum } & & & & 0.012 & 0.018 & 0.008 & 0.026 \\
\hline & & & & $(16.78)$ & $(25.96)$ & $(7.78)$ & $(27.66)$ \\
\hline \multirow[t]{2}{*}{ Low Momentum } & & & & -0.040 & -0.032 & -0.046 & -0.021 \\
\hline & & & & $(52.79)$ & (41.99) & $(41.74)$ & (19.73) \\
\hline \multirow[t]{4}{*}{ Constant } & .022 & .033 & .022 & .028 & .035 & .050 & .018 \\
\hline & $(42.90)$ & $(46.27)$ & (39.34) & (44.98) & $(43.25)$ & $(43.66)$ & $\begin{array}{c}(15.83) \\
5 / 1 / 07\end{array}$ \\
\hline & & & & & & $11 / 1 / 06$ & \\
\hline & AI & A I I & AI I & AI I & AI I & $\begin{array}{l}- \\
4 / 30 / 07\end{array}$ & $10 / 31 / 07$ \\
\hline Uoservations & ALL & ALL & ALL & ALL & ALL & $4 / 50 / 01$ & \\
\hline N obs & 1171428 & 1171428 & 1171428 & 1171428 & 1171428 & 531084 & 640344 \\
\hline R-squared & 0.0005 & 0.0058 & 0.0005 & 0.0046 & 0.0094 & 0.0094 & 0.0151 \\
\hline
\end{tabular}

* The dependent variable in each regression is the six-month score (the difference between the return for the pick and the return on the S\&P 500 index in the six months after the pick.) T-statistics for each regression coefficient are provided in parentheses. 
Column (1) of Table 5 presents the results for a model with only the player rating categories as independent variables. All-Star players have six-month pick scores that perform 1.7 percentage points higher on average than those of unrated players, translating into a difference of 3.4 percentage points in annual excess returns. As shown in Columns (2) through (5), the estimated effect of player ratings on pick score is little affected by including the other control variables. Allstar and Above Average players are estimated to perform significantly better than unrated players in every specification. Columns (6) and (7) split the sample into two time periods. The coefficients for the player rating variables prove to be much larger in magnitude for the second half of the sample. This result likely flows from our construction of player ratings. Since we have little or no information about the players at the beginning of the sample period, our estimated player ratings should be more accurate for the second half of the sample than for the first.

Consistent with the results in Tables 3 and 4, the coefficient for the S\&P 500 dummy variable in column (3) is small and statistically insignificant. This suggests that individual CAPS picks were about equally informative for S\&P 500 companies and for non-S\&P 500 companies. However, as highlighted in Columns (2) and (4) of Table 5, CAPS picks for Small Cap and Low Momentum stocks performed significantly worse than those for Medium Cap and Medium Momentum stocks respectively. Although CAPS participants were more likely to submit negative picks for Small Cap and Low Momentum stocks than for other stocks, these results indicate that they were not sufficiently pessimistic about these categories of stocks to offset the poor performance that stocks in these categories experienced during the sample period. The results in Columns (5), (6), and (7) show these pairwise relationships continue to hold when all three sets of variables are included as 
regressors, though there are some differences in magnitude of effects from the first six months of the sample (Column 6) to the second six months of the sample (Column 7).

\section{Preliminary Results: CAPS Percentile Ratings and Stock Performance}

CAPS offers the obvious potential benefit that it aggregates the information from many picks provided by disparate participants and summarizes the information in a transparent ranking system. If individuals possess valuable information on average, even if it is only a sliver of information per person, the CAPS system is well designed to uncover that fact. We report descriptive statistics for composition and performance by CAPS percentile ranking from three separate dates: (1) the first day of the sample period, November 1, 2006; (2) the midpoint of the sample period, May 1, 2007; and (3) the last day of the sample period, October 31, 2007.

Table 6a: Proportion of Large Cap Stocks in CAPS Portfolios

\begin{tabular}{|c|c|c|c|}
\hline & November 1, 2006 & May 1, 2007 & October 31, 2007 \\
\hline 1-Star & $19.6 \%$ & $12.0 \%$ & $6.8 \%$ \\
\hline 2-Stars & $24.4 \%$ & $17.7 \%$ & $15.6 \%$ \\
\hline 3-Stars & $31.1 \%$ & $23.2 \%$ & $19.7 \%$ \\
\hline 4-Stars & $30.0 \%$ & $24.3 \%$ & $23.6 \%$ \\
\hline 5-Stars & $20.2 \%$ & $17.3 \%$ & $22.3 \%$ \\
\hline All Ranked Stocks & $25.1 \%$ & $19.4 \%$ & $18.4 \%$ \\
\hline
\end{tabular}

Table 6b: Proportion of High Momentum Stocks in CAPS Portfolios

\begin{tabular}{|c|c|c|c|}
\hline & November 1, 2006 & May 1, 2007 & October 31, 2007 \\
\hline 1-Star & $26.2 \%$ & $20.6 \%$ & $9.6 \%$ \\
\hline 2-Stars & $32.9 \%$ & $28.1 \%$ & $15.9 \%$ \\
\hline 3-Stars & $33.4 \%$ & $30.8 \%$ & $26.2 \%$ \\
\hline 4-Stars & $29.7 \%$ & $31.5 \%$ & $34.8 \%$ \\
\hline 5-Stars & $33.6 \%$ & $32.0 \%$ & $50.6 \%$ \\
\hline All Ranked Stocks & $31.2 \%$ & $29.0 \%$ & $29.2 \%$ \\
\hline
\end{tabular}

Tables $6 \mathrm{a}$ and $6 \mathrm{~b}$ present descriptive statistics for changes in the composition of portfolios during the sample period. Though the portfolios were relatively similar in terms of market cap and momentum at the start of the sample period on November 1,2006, they changed considerably in 
character during the next year. ${ }^{11}$ In particular, by the end of the sample period, the One-Star portfolio came to include disproportionately few "Large Cap" companies and "High Momentum" stocks, whereas more than half of the stocks in the Five-Star portfolio were "High Momentum" stocks at that time. ${ }^{12}$ This change in portfolios suggests that CAPS participants were influenced by market returns favoring "Large Caps" and "High Momentum" stocks, but also that they were responding to these market conditions with a lag rather than anticipating them.

We tracked the future stock market returns for stocks with each CAPS rating on (1) November 1, 2006, (2) May 1, 2007, (3) October 31, 2007. For the purpose of reporting descriptive statistics, we followed the performance for each Star Rating of stocks three, six, nine, and twelve months into the future from each of these three start dates. We computed returns for individual stocks in simple fashion for each tracking period:

\section{Return(Stock_i) = (New_Price(Stock i) - Initial_Price(Stock_i)) / Initial_Price(Stock_i).}

We then computed average returns for stocks from each start date and tracking period for stocks with each CAPS rating. We exclude stocks that are listed with percentile ratings in the database for the initial date in any tracking period but that (1) did not have at least 20 recorded picks in the prior six months or (2) did not meet the CAPS criterion of $\$ 1.50$ (unadjusted) stock price and market cap of at least $\$ 100$ Million. ${ }^{13}$ Our analysis includes a total of 2,135 stocks with CAPS rankings on

\footnotetext{
${ }^{11}$ After the launch of CAPS on November 1, 2006, the system accumulated picks and was able to provide rankings for new stocks - primarily for small and medium cap stocks. As a result, the proportion of large caps among ranked stocks declined during the sample period.

${ }^{12}$ By definition, $30 \%$ of stocks are high momentum and $30 \%$ of stocks are low momentum at any given time.

${ }^{13}$ The CAPS website does not allow participants to submit picks for companies that have stock price below $\$ 1.50$ or market cap below $\$ 100$ Million, but it continues to list such companies with a (prior) CAPS rating both on the website and in the database provided for this study. So we used CRSP data to check these criteria and excluded companies that failed to meet them on the initial date for each separate six-month tracking period.
} 
November 1, 2006, 3,585 stocks with CAPS rankings on May 1, 2007, and 3,908 stocks with CAPS rankings on October $31,2007 .{ }^{14}$

In essence, we are assessing the performance of five separate portfolios of stocks, from One-Star to Five-Star stocks for up to one year. Our results may well understate the likely returns for an investment strategy based on CAPS ratings because we do not allow for any reallocation of stocks within a portfolio over a sample period, even though CAPS received a continuous flow of potentially informative picks during each sample period. In practice, for example, it would be natural to adjust a Five-Star portfolio of stocks to include stocks that become more attractive during the investment period, and remove stocks that dropped in rank.

Tables $7 \mathrm{a}$ through $7 \mathrm{c}$ present average stock returns for each time period and CAPS rating. For almost every combination of starting date and time elapsed, there is a strong and systematic relationship between CAPS rating and future performance. In general, Five-Star stocks perform best, Four-Star stocks next best, and so on, down to One-Star stocks performing worst. Further, the difference in performance from category to category appears to increase steadily over time, with Five-star stocks often achieving average annual returns of 20 percentage points or more higher than One-Star stocks. ${ }^{15}$ One interesting exception to this pattern is that the differences in twelvemonth future returns across categories are smaller than the differences in nine-month future returns across categories reported in Table 6c. This change in pattern corresponds to the tumultuous three

\footnotetext{
14 Though CAPS is designed to produce an equal number of stocks in each ranking category, our requirement of twenty or more picks in the previous six months produces a sample that includes somewhat more stocks with high CAPS ratings than those with low CAPS ratings for the second and third periods of analysis.

15 Note that the results reported in the table are averages for all stocks in a given category and are not annualized. Thus, the 14.8 percentage point average return for 5-star stocks in the six months after November 1, 2006 is equivalent to a 31.7 percentage point annual return after compounding.
} 
month trading period from August 1, 2008 to October 31, 2008, suggesting the possibility that CAPS picks may have been less informative during the period of financial crisis in the fall of 2008 and winter of 2008-2009 than during the previous 21 months (November 2006 through July 2007).

Table 7a: Return by Motley Fool Ranking for November 1, 2006

\begin{tabular}{|c|c|c|c|c|c|}
\hline & 1-Star & 2-Stars & 3-Stars & 4-Stars & 5-Stars \\
\hline 3 months & $6.9 \%$ & $8.3 \%$ & $7.8 \%$ & $8.7 \%$ & $8.6 \%$ \\
\hline 6 months & $8.3 \%$ & $10.3 \%$ & $11.9 \%$ & $13.1 \%$ & $14.8 \%$ \\
\hline 9 months & $2.5 \%$ & $8.1 \%$ & $13.6 \%$ & $13.0 \%$ & $16.1 \%$ \\
\hline 12 months & $8.5 \%$ & $14.9 \%$ & $23.2 \%$ & $22.1 \%$ & $28.2 \%$ \\
\hline \# of Stocks & 423 & 435 & 444 & 444 & 440 \\
\hline
\end{tabular}

Table 7b: Return by Motley Fool Ranking for May 1, 2007

\begin{tabular}{|c|c|c|c|c|c|}
\hline & 1-Star & 2-Stars & 3-Stars & 4-Stars & 5-Stars \\
\hline 3 months & $-9.0 \%$ & $-4.4 \%$ & $-1.5 \%$ & $0.6 \%$ & $1.5 \%$ \\
\hline 6 months & $-7.9 \%$ & $-0.3 \%$ & $6.1 \%$ & $8.9 \%$ & $12.1 \%$ \\
\hline 9 months & $-22.1 \%$ & $-13.6 \%$ & $-7.0 \%$ & $-3.4 \%$ & $-0.1 \%$ \\
\hline 12 months & $-24.5 \%$ & $-14.2 \%$ & $-7.3 \%$ & $-2.4 \%$ & $0.9 \%$ \\
\hline \# of Stocks & 598 & 655 & 733 & 806 & 745 \\
\hline
\end{tabular}

Table 7c: Return by Motley Fool Ranking for October 31, 2007

\begin{tabular}{|c|c|c|c|c|c|}
\hline & 1-Star & 2-Stars & 3-Stars & 4-Stars & 5-Stars \\
\hline 3 months & $-13.9 \%$ & $-14.2 \%$ & $-14.0 \%$ & $-12.2 \%$ & $-11.7 \%$ \\
\hline 6 months & $-19.8 \%$ & $-16.8 \%$ & $-15.9 \%$ & $-10.8 \%$ & $-9.3 \%$ \\
\hline 9 months & $-27.1 \%$ & $-22.2 \%$ & $-20.8 \%$ & $-15.6 \%$ & $-12.4 \%$ \\
\hline 12 months & $-45.6 \%$ & $-44.5 \%$ & $-41.4 \%$ & $-40.1 \%$ & $-40.2 \%$ \\
\hline \# of Stocks & 618 & 717 & 802 & 879 & 889 \\
\hline
\end{tabular}

Table 8 combines all three six-month periods to provide comparisons of performance across CAPS rating for different subgroups of stocks. ${ }^{16}$ For every subgroup of stocks, Five-Star stocks performed best, Four-Star stocks performed second-best, and so on down to One-Star stocks performing worst. With the sole exceptions of Medium Cap and "No Momentum" stocks, the

\footnotetext{
${ }^{16}$ The tabulations in the table give equal weight to each three month period, so for example, the value $-6.5 \%$ reported for 1-star stocks in the first row is the average of the six month returns of $8.3 \%,-7.9 \%$, and $-19.8 \%$ reported for 1-star stocks in Tables $7 \mathrm{a}, 7 \mathrm{~b}$, and $7 \mathrm{c}$ for three different start dates.
} 
difference in six month performance between Five-Star and One-Star stocks in is always at least ten percentage points, corresponding to annualized differences of more than twenty percentage points.

Table 8: Six Month Returns by Motley Fool Ranking

\begin{tabular}{|c|c|c|c|c|c|}
\hline & 1-Star & 2-Stars & 3-Stars & 4-Stars & 5-Stars \\
\hline All Stocks & $-6.5 \%$ & $-2.3 \%$ & $0.7 \%$ & $3.7 \%$ & $5.9 \%$ \\
\hline S\&P 500 & $-6.0 \%$ & $-2.5 \%$ & $2.3 \%$ & $5.5 \%$ & $6.1 \%$ \\
\hline & & & & & \\
\hline Large Cap & $-6.6 \%$ & $-1.5 \%$ & $4.5 \%$ & $6.7 \%$ & $8.7 \%$ \\
\hline Med. Cap & $-0.9 \%$ & $2.0 \%$ & $2.8 \%$ & $5.8 \%$ & $7.4 \%$ \\
\hline Small Cap & $-8.7 \%$ & $-5.5 \%$ & $-3.0 \%$ & $0.3 \%$ & $3.5 \%$ \\
\hline High Mom & $-7.3 \%$ & $-1.5 \%$ & $1.8 \%$ & $4.4 \%$ & $8.5 \%$ \\
\hline No Mom & $-2.2 \%$ & $-0.6 \%$ & $2.4 \%$ & $6.3 \%$ & $7.1 \%$ \\
\hline Low Mom & $-9.7 \%$ & $-4.6 \%$ & $-3.5 \%$ & $-1.3 \%$ & $3.0 \%$ \\
\hline
\end{tabular}

\section{Regression Analysis and the Fama-French Model}

We formalize the comparisons suggested by Tables 7 and 8 using a four factor regression model.

Fama and French (1996) identified three measures that have been demonstrated to be predictive of future stock returns. The first of these factors is the "Market Return" less the risk free rate, RMRF, which controls for correlation between the returns in a portfolio of individual stocks and the returns on the market portfolio. (For example, this correlation would likely be quite high for a portfolio of high-beta stocks, indicating a high-risk portfolio.) The second factor is a value/growth factor, HML, which controls for the composition of a portfolio of stocks in terms of book value relative to market value. The third factor is a small stock factor, SMB, which controls for the composition of a portfolio of stocks in terms of market cap value. We use the three factors identified by Fama and French in our analysis along with a fourth factor, "Momentum", identified by Carhart (1997). The Momentum factor controls for the composition of a portfolio of stocks in terms of previous year's stock market performance. 
To examine whether stock returns for a particular portfolio are attributable to these factors, we regress the one-day return of the portfolio of interest less the risk free rate on the contemporaneous values of these four factors. ${ }^{17}$ We construct the portfolios of interest based on CAPS rating for each of three six-month sample periods. Combining these sample periods, we are able to compute the one-day returns for each of the 5 rating portfolios for each trading day from November 1, 2006 to May 1, 2008. There are 375 trading days under study. Crucially, each of the portfolios receives its own weighting or coefficient on each of these factors so that the resulting "excess return" of the high-CAPS portfolio is, in effect, net of these other well-known factors.

Table 9 presents the results. For each of the first 5 columns, the dependent variable is the one-day return for a given CAPS percentile portfolio minus the risk free rate. The independent variables are the market factor less the risk free rate (RMRF), the market capitalization factor (SMB), the value/growth factor (HML), and the momentum factor (Mom). The right hand side variable of most interest is "Alpha", the residual performance unexplained by the style factors. If the Alpha coefficient for a portfolio is significantly positive, it means that the portfolio outperforms the factor-adjusted market return over the time period of our data.

\footnotetext{
${ }^{17}$ The values for these factors represent the market returns for separate portfolios explicitly designed to correspond to each separate factor. We downloaded the daily values for these factors for the time period for our sample from Kenneth French's website: http://mba.tuck.dartmouth.edu/pages/faculty/ken.french/data_library.html
} 
Table 9: Regression Coefficients for Individual Portfolios in the Four-Factor Model

\begin{tabular}{|c|c|c|c|c|c|c|c|c|c|c|}
\hline & (1) & (2) & (3) & (4) & (5) & (6) & (7) & $(8)$ & $(9)$ & $(10)$ \\
\hline \multirow[t]{2}{*}{ RMRF } & 0.94 & 1.00 & 1.00 & 1.03 & 1.066 & 0.122 & 0.963 & 1.049 & 0.886 & 1.088 \\
\hline & $(0.013)$ & $(0.009)$ & $(0.009)$ & $(0.010)$ & $(0.011)$ & $(.016)$ & $(0.016)$ & $(0.013)$ & $(0.022)$ & $(0.027)$ \\
\hline \multirow[t]{2}{*}{ SMB } & 0.779 & 0.642 & 0.512 & 0.430 & 0.412 & -0.367 & 0.738 & 0.458 & 0.873 & 0.333 \\
\hline & $(0.033)$ & $(0.024)$ & $(0.023)$ & $(0.026)$ & $(0.029)$ & $(.040)$ & $(0.039)$ & $(0.033)$ & $(0.055)$ & $(0.066)$ \\
\hline \multirow[t]{2}{*}{ HML } & 0.114 & 0.034 & -0.029 & -0.023 & 0.048 & -0.066 & 0.016 & 0.113 & 0.184 & -0.010 \\
\hline & $(0.045)$ & $(0.034)$ & $(0.031)$ & $(0.036)$ & $(0.041)$ & $(0.055)$ & $(0.058)$ & $(0.049)$ & $(0.068)$ & $(0.082)$ \\
\hline \multirow[t]{2}{*}{ Mom } & -0.275 & -0.112 & 0.042 & 0.189 & 0.296 & 0.571 & -0.212 & 0.308 & -0.336 & 0.297 \\
\hline & $(0.018)$ & $(0.014)$ & $(0.013)$ & $(0.015)$ & $(0.017)$ & $(0.022)$ & $(0.030)$ & $(0.025)$ & $(0.025)$ & $(0.031)$ \\
\hline \multicolumn{11}{|l|}{ Estimated } \\
\hline \multirow[t]{2}{*}{ Alpha } & -0.042 & -0.022 & -0.012 & 0.003 & 0.013 & 0.055 & -0.046 & 0.019 & -0.068 & 0.001 \\
\hline & $(0.013)$ & $(0.010)$ & (0.009) & $(0.010)$ & $(0.012)$ & $(0.016)$ & $(0.015)$ & $(0.013)$ & $(0.025)$ & $(0.030)$ \\
\hline Portfolio & \%ile 1 & \%ile 2 & \%ile 3 & \%ile 4 & $\%$ ile 5 & $5-1$ & \%ile 1 & $\%$ ile 5 & \%ile 1 & \%ile 5 \\
\hline Sample & \multicolumn{5}{|c|}{ ALL } & ALL & \multicolumn{2}{|c|}{$11 / 1 / 06-12 / 31 / 07$} & \multicolumn{2}{|c|}{$12 / 31 / 07-5 / 1 / 08$} \\
\hline $\mathrm{N}$ obs & 375 & 375 & 375 & 375 & 375 & 375 & 292 & 292 & 83 & 83 \\
\hline R-squared & 0.96 & 0.98 & 0.98 & 0.97 & 0.96 & 0.72 & 0.94 & 0.96 & 0.98 & 0.97 \\
\hline
\end{tabular}

* Standard errors for each regression coefficient are provided in parentheses.

Table 9 provides several interesting results. First, by working backwards from the regression coefficients in columns (1) through (5), we can infer differential characteristics of stocks in each portfolio. Of particular note, higher-rated stocks have larger regression coefficients for both the market return (RMRF) and for the momentum variable. The comparison of these coefficients suggests that in fact, higher-rated stocks covary more closely with excess market return (and thus are more risky than lower-rated stocks). Further, (and consistent with the descriptive statistics presented in our earlier analysis in Table 6b), the coefficients on the momentum variables indicate that some of the difference in performance between higher-rated and lower-rated CAPS stocks is due to the strong correlation between "Momentum" and the CAPS rating. 
Columns (1) and (2) of Table 9 show that, after accounting for known factors, stocks with the worst CAPS ratings (Percentile portfolios 1 and 2) have (statistically significant) negative Alphas. In particular, the Alpha coefficient in column (1) indicates negative excess returns of $0.42 \%$ per trading day for One-Star stocks, which is equivalent to an annualized negative excess return of approximately $10 \% .{ }^{18}$ By comparison, columns (4) and (5) show that the portfolio of stocks with the highest CAPS ratings players (Percentile Portfolios 4 and 5) have positive Alphas, but these are not statistically significant at standard confidence levels.

Column (6) of Table 9 uses the same regression framework as Columns (1) through (5), but with a dependent variable equal to the difference in daily returns between Portfolio 5 and Portfolio 1. Thus, the Alpha coefficient in column (6) represents the excess return earned by simultaneously buying Five-Star stocks and shorting One-Star stocks. This strategy produces a statistically significant estimated Alpha, corresponding to an annualized excess return of approximately $15 \%$.

Columns (7)-(8) and Columns (9)-(10) of Table 9 compare just Portfolio 1 and Portfolio 5 for two different time periods of the data. Columns (7) and (8) show regression results for the bull market period from the beginning of the sample through 12/31/07, while Columns (9) and (10) look at the short bear market period from January 2008 through April 2008. The market rose overall during the first sub-period and fell slightly during the second sub-period. The results show that a portfolio of the highest rated CAPS stocks outperformed a portfolio of the lowest rated CAPS stocks in both of these sub-periods, corresponding to a difference in annualized returns of approximately $16 \%$ during the first sub-period and approximately $17 \%$ during the second sub-period.

\footnotetext{
${ }^{18}$ We convert one-day returns to annualized returns based on an estimated 250 trading days per year.
} 
We extend the regression specification employed in Table 9 to estimate Alpha coefficients for all five portfolios at once. This framework allows us to explore the relative importance of each individual explanatory market factor in relationship to the estimated Alpha coefficients of each portfolio. We interact the market factors with dummy variables for each of the portfolios so that each portfolio has its own weighting or coefficient with each market factor. Thus, for example, the coefficient for "RMRF-1" represent the weighting of the One-Star portfolio with RMRF and similarly the coefficient for "Mom-1" represents the weighting of the One-Star portfolio with the Momentum variable. Table 10 presents our results.

Columns (1) through (4) of Table 10 use a linear specification for the number of stars for each portfolio, thereby constraining the difference in estimated Alpha between one-star and two-star, two-star and three-star, three-star and four-star, four-star and five-star Alpha coefficients to be exactly the same. We include the RMRF factor in each specification, but do not include any other market factors in the specification of column (1). Column (2) adds the Momentum market factor as an independent variable, column (3) adds instead the HML and SMB factors, and column (4) includes all four market factors. We highlight the importance of the RMRF and Momentum factors by reporting the coefficients for each of these factors in combination with each of portfolios 1 through 5 stars in Table 10. 
Table 10: Regression Coefficients for the Extended Four-Factor Model

\begin{tabular}{|c|c|c|c|c|c|c|c|}
\hline & (1) & (2) & (3) & (4) & (5) & (6) & (7) \\
\hline \multirow[t]{2}{*}{ RMRF-1 } & 1.04 & 0.97 & 0.99 & 0.94 & 0.94 & 0.96 & 0.89 \\
\hline & $(.017)$ & $(.015)$ & $(.013)$ & $(.011)$ & $(.011)$ & $(.012)$ & $(.022)$ \\
\hline \multirow[t]{2}{*}{ RMRF-2 } & 1.06 & 1.03 & 1.02 & 1.00 & 1.00 & 1.01 & 0.97 \\
\hline & $(.017)$ & $(.015)$ & $(.013)$ & $(.011)$ & $(.011)$ & $(.012)$ & $(.022)$ \\
\hline \multirow[t]{2}{*}{ RMRF-3 } & 1.03 & 1.02 & 0.99 & 1.00 & 1.00 & 1.01 & 0.96 \\
\hline & $(.017)$ & $(.015)$ & $(.013)$ & $(.011)$ & $(.011)$ & $(.012)$ & $(.022)$ \\
\hline \multirow[t]{2}{*}{ RMRF-4 } & 1.03 & 1.05 & 1.00 & 1.03 & 1.03 & 1.02 & 1.03 \\
\hline & $(.017)$ & $(.015)$ & $(.013)$ & $(.011)$ & $(.011)$ & $(.012)$ & $(.022)$ \\
\hline \multirow[t]{2}{*}{ RMRF-5 } & 1.04 & 1.08 & 1.02 & 1.07 & 1.07 & 1.05 & 1.09 \\
\hline & $(.017)$ & $(.015)$ & (.013) & $(.011)$ & $(.011)$ & $(.012)$ & $(.022)$ \\
\hline \multirow[t]{2}{*}{ Mom-1 } & & -.366 & & -.275 & -.275 & -.211 & -.336 \\
\hline & & $(.021)$ & & $(.015)$ & $(.015)$ & $(.024)$ & $(.026)$ \\
\hline \multirow[t]{2}{*}{ Mom-2 } & & -.178 & & -.112 & -.112 & -.057 & -.155 \\
\hline & & $(.021)$ & & $(.015)$ & $(.015)$ & (.024) & $(.026)$ \\
\hline \multirow[t]{2}{*}{ Mom-3 } & & -.004 & & .042 & .042 & .102 & -.013 \\
\hline & & $(.021)$ & & $(.015)$ & $(.015)$ & $(.024)$ & $(.026)$ \\
\hline \multirow[t]{2}{*}{ Mom-4 } & & .150 & & .189 & .189 & .236 & .161 \\
\hline & & $(.021)$ & & $(.015)$ & $(.015)$ & $(.024)$ & $(.026)$ \\
\hline \multirow[t]{2}{*}{ Mom-5 } & & .250 & & .296 & .296 & .308 & .297 \\
\hline & & $(.021)$ & & $(.015)$ & $(.015)$ & (.024) & $(.026)$ \\
\hline \multirow[t]{2}{*}{ Alpha / Rank } & .025 & .015 & .019 & .013 & & & \\
\hline & $(.006)$ & $(.005)$ & $(.004)$ & $(.003)$ & & & \\
\hline \multirow[t]{2}{*}{ 2-Star Stock } & & & & & .020 & .017 & .044 \\
\hline & & & & & $(.015)$ & $(.017)$ & $(.036)$ \\
\hline \multirow[t]{2}{*}{ 3-Star Stock } & & & & & .030 & .037 & .025 \\
\hline & & & & & $(.015)$ & (.017) & $(.036)$ \\
\hline \multirow[t]{2}{*}{ 4-Star Stock } & & & & & .045 & .048 & .066 \\
\hline & & & & & $(.016)$ & $(.017)$ & $(.036)$ \\
\hline \multirow[t]{2}{*}{ 5-Star Stock } & & & & & .055 & .065 & .070 \\
\hline & & & & & $(.015)$ & $(.017)$ & $(.036)$ \\
\hline \multirow[t]{3}{*}{ Constant } & -.099 & -.069 & -.068 & -.052 & -.042 & -.046 & -.068 \\
\hline & $(.019)$ & $(.017)$ & $(.014)$ & $(.011)$ & $(.011)$ & $(.012)$ & $(.025)$ \\
\hline & & & & & & $11 / 1 / 06$ & $1 / 1 / 08$ \\
\hline Sample & ALL & ALL & ALL & ALL & ALL & $\begin{array}{r}\text { to } \\
12 / 31 / 07\end{array}$ & $\begin{array}{r}\text { to } \\
5 / 1 / 08\end{array}$ \\
\hline HML 1 to 5 & NO & NO & YES & YES & YES & YES & YES \\
\hline SMB 1 to 5 & NO & NO & YES & YES & YES & YES & YES \\
\hline $\mathrm{N}$ obs & 1875 & 1875 & 1875 & 1875 & 1875 & 1460 & 415 \\
\hline R-squared & 0.91 & 0.93 & 0.95 & 0.97 & 0.97 & 0.96 & 0.98 \\
\hline
\end{tabular}

* Standard errors for each regression coefficient are provided in parentheses. 
The estimated Alpha coefficient in columns (1) through (4) of Table 10 represent the estimated difference in market returns per day for a portfolio of stocks with a given CAPS ranking and a portfolio of stocks one star below. In column (1), for example, controlling only for interactions with market returns, the estimated Alpha coefficient of .025 corresponds to annualized excess returns of $6.25 \%$ per increase of one-star in portfolio, meaning that the Five-Star portfolio would be estimated to outperform the One-Star portfolio by approximately $25 \%$ on an annualized basis. Comparing the results of columns (1) through (4), we find that including each additional market factor in the regression specification reduces the estimated Alpha coefficient per portfolio rank, but that including the Momentum factor has most effect on the estimated Alpha coefficient. Once again, these results highlight the connection between Momentum and CAPS rating. The estimated Alpha coefficients in each of columns (1) through (4) are positive and statistically significant at the $1 \%$ level.

In column (5) of Table 10, we include dummy variables to estimate Alpha coefficients for each individual portfolio relative to the One-Star (omitted) portfolio. The fitted coefficients of .020, $.030, .045$, and .055 for Two-Star through Five-Star portfolios translate into annualized excess returns of approximately 5\% (Two-Star), 7\% (Three-Star), 11\% (Four-Star), and 14\% (Five-Star) relative to the One-Star portfolio; these results quite closely match the results from column (4), where all four market factors were also included as independent variables in the regression. Finally, we estimate Alpha coefficients for the bull and bear market subperiods of our sample in columns (6) and (7). In these regressions, the estimated Alpha coefficients for Four-Star and FiveStar stocks are positive and statistically significant, representing excess returns relative to One-Star stocks, though they are only statistically significant at the $10 \%$ level in column (7) due to the short 
time period of the bear market period in our sample. In columns (5) and (6), the estimated Alpha coefficients for portfolios 2 through 5 are jointly statistically significant at the $1 \%$ level.

One apparent anomaly in both Tables 9 and 10 is that we generally estimate larger Alpha coefficients in magnitude for each subperiod of trading than for the entire period of trading. For example, the estimated Alpha coefficient for the 1-Star portfolio is more negative in each of columns (7) and (9) than in column (1) of Table 9. Comparing the regression coefficients in columns (7) and (9) in Table 9, the One-Star portfolio is estimated to have lower covariance with RMRF and larger negative covariance with Momentum in the second subperiod than in the first subperiod of trading. However, the regression specification in columns (1) through (6) of Table 9 constrains the coefficients for each market factor to be constant for the entire sample period, thereby producing an estimated Alpha coefficient in column (1) that appears to somewhat understate the negative excess returns for One-Star stocks.

To account for these likely differences in correlation between portfolios and market factors over time, we further extend the framework of Table 10 to allow different coefficients for each combination of market factor, portfolio, and six month trading period. Table 11 reports the estimated Alpha coefficients for regressions that incorporate all stocks as well as for subgroups of stocks based on market cap and inclusion in the S\&P 500. Once again Table 11 produces generally produces estimated Alpha coefficients that increase with CAPS ranking for each subset of stocks. These Alpha coefficients are statistically significant for Five-Star stocks at the $1 \%$ level for all stocks, large caps and small caps, at the $5 \%$ level for medium cap stocks and at the $10 \%$ level for S\&P 500 companies. 
In terms of annualized returns, the fitted coefficients in Table 11 translate to excess returns for Five-Star portfolio relative to the One-Star portfolio of approximately $18 \%$ for all stocks (column 1), $9 \%$ for S\&P 500 stocks (column 2), 18\% for large cap stocks (column 3), $8 \%$ for medium cap stocks (column 4), and 20\% for small cap stocks (column 5). Although these coefficients reflect some differences in estimated performance across types of stocks, it still seems notable that we find statistically significant excess returns based on the CAPS rankings for each of large, medium, and small cap stocks even though the portfolios used to compute these returns are completely distinct.

These findings, which suggest that CAPS participants are more likely to have payoff-relevant information for companies that are least known, since the estimated Alphas for each portfolio are higher for "Small Caps" than for any other subset of companies, are consistent to some degree with the prior literature. A prime distinction from the prior literature is the finding that the Three-, Fourand Five-Star portfolios have such large and significant estimated Alphas for "Large Cap" stocks. ${ }^{19}$

\footnotetext{
${ }^{19}$ The sharp difference in results for S\&P 500 and "Large Cap" stocks is surprising given that there is considerable overlap between these two groups of companies. Further investigation suggests that this difference stems from a few factors. First, there were relatively few large cap companies with a one-star ranking in the last six months of the sample. Second, the large cap companies which had a one-star ranking on October 31, 2007 that were not in the S\&P 500 tended to be airlines and cell phone companies, which performed unusually poorly in the next six months. As a result, one-star Large Cap stocks performed worse overall than one-star S\&P 500 stocks.
} 
Table 11: Regression Coefficients: Six Month Returns for Subsamples of Stocks

\begin{tabular}{|l|ccccc|}
\hline & $(1)$ & $(2)$ & $(3)$ & $(4)$ & $(5)$ \\
\hline 2-Star Stock & .032 & -.001 & .025 & .007 & .034 \\
& $(.014)$ & $(.019)$ & $(.019)$ & $(.018)$ & $(.022)$ \\
3-Star Stock & .043 & .023 & .056 & .013 & .035 \\
& $(.014)$ & $(.019)$ & $(.019)$ & $(.018)$ & $(.022)$ \\
4-Star Stock & .060 & .040 & .068 & .021 & .059 \\
& $(.014)$ & $(.019)$ & $(.019)$ & $(.018)$ & $(.022)$ \\
5-Star Stock & .073 & .035 & .072 & .035 & .080 \\
& $(.014)$ & $(.019)$ & $(.019)$ & $(.018)$ & $(.022)$ \\
Sample & ALL & S\&P 500 & Large Cap & Med. Cap & Small Cap \\
Joint Significance, & & & & & \\
2 Star-5 Star & & & & & \\
Coefficients & $0.00 \%$ & $10.3 \%$ & $0.00 \%$ & $32.4 \%$ & $0.00 \%$ \\
N obs & 1875 & 1875 & 1875 & 1875 & 1875 \\
R-squared & 0.97 & 0.96 & 0.96 & 0.96 & 0.94 \\
\hline
\end{tabular}

\section{Sensitivity Analysis}

Several features of our database restricted our analysis. First, we primarily analyzed the relationship between CAPS rankings and stock performance, but we cannot recreate these rankings from the database provided for the paper. Second, we compute results for the first six months of trading in our sample period (11/1/2006 to 6/1/2007), based on CAPS rankings from November 1 , 2006, the date that the website was launched. However, our database does not include any records of the picks used to generate the November 1, 2006 rankings. Further, those CAPS rankings were probably not representative, as they were based on picks provided during a trial period of CAPS. Third, our comparisons between performance of "1 Star" and "5 Star" stocks implicitly assume a trading strategy of buying 5-Star stocks and short-selling 1-Star stocks. However, since a majority of 1-Star stocks are "Small Caps", it is likely that many of them cannot actually be short-sold. 
This section reports the results of sensitivity analysis designed to assess the importance of these limitations of the data, and potential critiques of our results associated with these limitations.

\section{Sentiment Ratings}

To anticipate the critique that researchers cannot reconstruct the CAPS ratings from the database of picks, we construct our own rankings for stocks in the sample based on "Sentiment Rating". We define Sentiment Rating based on the percentage of positive picks in each six month period of the sample, giving equal weight to each pick for a given stock during that time period. This intentionally simplistic procedure has the important virtue that it is straightforward to create sentiment ratings from the picks data.

To adjust for the fact that different stocks receive different numbers of picks in each sample period, we first compute a Sentiment Cardinal Rating for each stock based on the (binomial distribution) probability of achieving a given percentage of positive picks at random based on the underlying proportion of positive picks in the sample. We then convert these cardinal rankings into ordinal rankings from one to five. Each rank corresponds to a quintile of stocks based on Sentiment Cardinal Ranking.

\section{$\underline{\text { Alternate Start Period }}$}

Acknowledging the critique that the November 1,2006 CAPS rankings are not representative, since they were based on picks from a trial period of the website, we also compute results based on an alternative start date of January 1, 2007, when the website had been in operation for two months. This start date ensures that our database includes a record of the most recent picks used by CAPS to 
generate the January 1, 2007 rankings, and offers the additional advantage of matching our sample period to calendar years and half-years. Given this start date, our three six-month subperiods of trading begin on January 1, 2007, July 1, 2007, and January 1, 2008; thus our eighteen month sample period for stock returns runs from January 1, 2007 to June 30, 2008. Since our data for CAPS ratings only runs through October 31, 2007, we use these October 31, 2007 ratings as proxies for the January 1, 2008 CAPS ratings in the analysis of portfolio returns.

\section{Further Restrictions on Including Small Cap Stocks}

To adjust for the fact that some stocks cannot be sold short, we strengthen the rule for inclusion in the sample by eliminating stocks with trading prices below $\$ 5.00$ per share (rather than $\$ 1.50$ per share, the formal rule for inclusion in CAPS). We also eliminate stocks that have suffixes ".OB", “.PK", or ".L" in trading symbol, suffixes indicating that these are not available for ordinary trading on the New York Stock Exchange (NYSE). These two sets of stocks - those with low prices and those not exchanged on the NYSE -- tend to be illiquid and are often not available for short-selling.

Table 12 reports the results for each of these changes in sample for portfolio analysis. Column (2) reports the results of regression analysis for a four factor model based on sentiment ratings. Column (3) reports the results for eighteen months of trading based on the alternate start date of January 1, 2007. In each case, the new results are nearly identical to the results in Column (1), which repeats the coefficients from Table 11 for the full sample based on CAPS ratings. 
Column (4) of Table 12 reports the results for portfolio analysis based on the restricted sample of stocks, excluding stocks not traded on the NYSE and stocks with trading prices below $\$ 5$ per share. With this restriction, the difference in returns between Five-Star and One-Star stocks remains statistically significant, though somewhat reduced in magnitude. This finding is consistent with the finding in Table 11 that the relationship between CAPS rankings and market returns are weakest for "Medium Cap" stocks. By strengthening the requirements for inclusion in the portfolios for analysis, we primarily eliminate "Small Cap" stocks, thus increasing the overall weight placed on "Medium Caps", and thereby reducing the assessed difference in market returns between high and low-rated CAPS stocks.

Table 12: Regression Coefficients for Sensitivity Analysis Specifications

\begin{tabular}{|l|cccc}
\hline & & & & $(3)$ \\
& $(1)$ & $(2)$ & $(4)$ \\
\hline 2-Star Stock & .032 & .042 & .039 & .020 \\
3-Star Stock & $.014)$ & $(.015)$ & $(.015)$ & $(.013)$ \\
& .043 & .046 & .042 & .030 \\
4-Star Stock & $(.014)$ & $(.015)$ & $(.015)$ & $(.013)$ \\
& .060 & .062 & .056 & .042 \\
5-Star Stock & $(.014)$ & $(.015)$ & $(.015)$ & $(.013)$ \\
& .073 & .075 & .067 & .054 \\
Description & $(.014)$ & $(.015)$ & $(.015)$ & $(.013)$ \\
Joint Significance, & & Sentiment & $1 / 1 / 2007$ to & No Suffix, \\
2 Star-5 Star & ALL & Ratings & $6 / 30 / 2008$ & Price $\geq \$ 5$ \\
Coefficients & & & & \\
N obs & $0.00 \%$ & $0.00 \%$ & $0.00 \%$ & $0.00 \%$ \\
R-squared & 1875 & 1875 & 1880 & 1875 \\
& 0.97 & 0.96 & 0.97 & 0.98 \\
\hline
\end{tabular}




\section{Conclusion}

We find consistent evidence that CAPS picks yield information that predicts future stock market returns for individual stocks. Results from the four-factor model indicate that CAPS participants tend to make positive recommendations for stocks that are relatively risky (and thus highly correlated with market returns) and for stocks that have performed well in the past year ("high momentum stocks"). These tendencies, particularly the positive correlation between Momentum and CAPS picks, explain some of the absolute differences in performance shown in the descriptive statistics in Sections 3 and 4. Still, we find statistically significant excess returns in our preferred specification (column 1 of Table 11) of 18 percentage points for the highest-rated stocks relative to the lowest-rated stocks. These excess returns are of a greater order of magnitude than those from any previous study in the literature, which typically finds excess returns on the order of substantial basis points rather than double-digit percentage points. Another novel feature of our findings is that CAPS predictions yield excess returns over a lengthy time horizon, rather than in a short window of hours or days of trading. Both of these results suggest that CAPS participants possess price-relevant information that is far from systematically incorporated in market prices.

One cautionary finding is that our sample period directly precedes the financial crisis of late-2008 and 2009. Thus, it is of particular import and interest to extend analysis to the present when additional data about CAPS picks beyond October 31, 2007 becomes available. 


\section{REFERENCES}

Antweiler, Werner and Murray Z. Frank (2004a), "Is All That Talk Just Noise? The Information Content of Internet Stock Message Boards," Journal of Finance, 59(3), June 2004, p. 1259-1294.

Antweiler, Werner and Murray Z. Frank (2004b), "Does Talk Matter? Evidence from a Broad Cross Section of Stocks," working paper, 2004.

http://webpages.csom.umn.edu/finance/mfrank/WorkingPapers/Talk_Sept2004.pdf

Bagnoli, Mark, Messod Daniel and Susan G. Watts, "Whisper Frecasts of Quarterly Earnings per Share", Journal of Accounting and Economics, 28(1), August 1999, p. 27-50.

Barber, Brad M., Terrance Odean,, and Ning Zhu, “Do Noise Traders Move Markets?”, working paper, UC Davis and UC Berkeley. 2006.

Barber, Brad M. and Terrance Odean (2001a), "Boys will be Boys: Gender, Overconfidence, and Common Stock Investment" with Brad Barber, Quarterly Journal of Economics, February 2001, 116(1), p. 261-292.

Barber, Brad M. and Terrance Odean (2001b), “The Internet and the Investor,” Journal of Economic Perspectives, 15(1), Winter 2001, p. 41-54.

Barber, Brad M. and Terrance Odean (2000), "Trading is Hazardous to Your Wealth: The Common Stock Investment Performance of Individual Investors" Journal of Finance, 55(2), April 2000, p. 773-806.

Chevalier, Judith A. and Glenn Ellison, “Are Some Mutual Fund Managers Better than Others? Cross-Sectional Patterns in Behavior and Performance," Journal of Finance, 54(3), June, 1999, p, 875-899.

Coval, Joshua, David Hirshleifer, and Tyler Shumway, "Can Individual Investors Beat the Market?" working paper, Harvard University, 2005.

Das, Sanjiv R. and Mike Y. Chen, "Yahoo! for Amazon: Sentiment Extraction from Small Talk on the Web”, Management Science, 53(9), September 2007, p. 1375-1388.

Frieder, Laura and Jonathan Zittrain, "Spam Works: Evidence from Stock Touts and Corresponding Market Activity," working paper, Harvard University, 2007.

Hogarth, Robin, "Methods for Aggregating Opinions," in Helmut Jungerman \& Gerald de Zeeuw (eds.), Decision Making and Change in Human Affairs, D. Reidel Publishing Co., Dordrecht, Holland, 1977., p. 231-255.

Ivković, Zoran and Scott Weisbenner, "Local Does as Local Is: Information Content of the Geography of Individual Investors' Common Stock Investments", Journal of Finance, 60(1), February, 2005, p. 267-306. 
Ivković, Zoran, Clemens Sialm, and Scott Weisbenner, "Portfolio Concentration and the Performance of Individual Investors", Journal of Financial and Quantitative Analysis, 43(3), September, 2008, p. 613-656.

Linstone, Harold A. and Murray Turoff (eds.), The Delphi Method: Techniques and Applications. Addison-Wesley, Reading, Ma., 1975.

Metrick, Andrew, "Performance Evaluation with Transactions Data: The Stock Selection of Investment Newsletters," Journal of Finance, 54(5), October, 1999, p. 1743-1775.

Massa, Massimo and Andrei Simonov, "Hedging, Familiarity, and Portfolio Choice," Review of Financial Studies, 19(2), Summer 2006, p.633-686.

Mikhail, Michael B., Beverly R. Walther and Richard H. Willis, "Do Security analysts Exhibit Persistent Differences in Stock Picking Ability?," Journal of Financial Economics, 74(1), February 2004, p. 67-91.

Resnick, Paul and Richard Zeckhauser, "Trust Among Strangers in Internet Transactions: Empirical Analysis of eBay's Reputation System," in The Economics of the Internet and E-Commerce, M. R. Baye (ed.), Amsterdam: Elsevier Science, 2002, 127-157.

Sabherwal, Sanjiv, Salil Sarkar and Ying Zhang, "Online Talk: Does It Matter?” Managerial Finance, 34 (6), 2008, p. 423-426.

Sunstein, Cass, "Deliberation and Information Markets, in Robert Hahn and Paul Tetlock (eds.), Information Markets: A New Way of Making Decisions, AEI Press, Washington, D.C., 2006, p. $\underline{67-99 .}$

Tetlock, Paul, "Giving Content to Investor Sentiment: The Role of Media in the Stock Market," Journal of Finance, 62(3), May 2007, p. 1139-1168.

Tumarkin, Robert and Robert Whitelaw, "New or Noise? Internet Postings and Stock Prices," Financial Analysts Journal 57(3), May/June 2001, p. 41-51.

Wolfers, Justin and Eric Zitzewitz, "Prediction Markets," The Journal of Economic Perspectives 18(2), 2004, p. 107-126. 